\title{
B Subunit of Human Chorionic Gonadotropin Promotes Tumor Invasion and Predicts Poor Prognosis of Early-Stage Colorectal Cancer
}

\author{
Jiali Lia,b Mingzhu Yin ${ }^{\mathrm{b}}$ Wanjing Song ${ }^{\mathrm{a}}$ Fengyun Cui ${ }^{\mathrm{a}} \quad$ Wei Wang ${ }^{\mathrm{a}}$ \\ Shuyang Wang ${ }^{\mathrm{a}}$ Hongguang Zhu ${ }^{\mathrm{a}}$ \\ aDepartment of Pathology, School of Basic Medical Sciences, Fudan University, Shanghai, China; \\ ${ }^{b}$ Department of Pathology, Yale School of Medicine, New Haven, CT, USA
}

\section{Key Words}

Early-stage CRC • $\beta$-HCG $•$ Prognosis • Invasion • Epithelial-Mesenchymal Transition (EMT)

\begin{abstract}
Background/Aims: It is well established that many non-trophoblastic tumors secrete HCG (human chorionic gonadotropin) and that such secretion is correlated with the poor prognosis of tumor patients. This study aims to analyze the correlation between $\beta-\mathrm{HCG}$ expression and outcome of colorectal cancer (CRC) and understand its role in CRC pathology. Methods: We detected the mRNA and protein expression of $\beta$-HCG in human CRC tissues with RT-qPCR and immunohistochemistry, and we compared the clinical-pathological characteristics, prognosis and progression between the $\beta$-HCG positive and negative groups. We also generated CRC cell lines with $\beta-\mathrm{HCG}$ over-expression as well as $\beta$-HCG stable knockout, and evaluated cell function and mechanism in vitro and in vivo. Results: Fifty out of 136 CRC patients (37\%) expressed $\beta-H C G$ at the invasive front. Clinical-pathological data showed that $\beta-H C G$ was positively correlated with Dukes staging $(P=0.031)$ and lymph node metastasis $(P=0.012)$. Survival analysis suggested that the patients with high expression of $\beta$-HCG had poorer prognosis than those with low $\beta-H C G$ expression $(P=0.0289)$. $\beta-H C G$ expression level was also positively correlated with tumor invasion in early-stage CRC patient tissues $(P=0.0227)$. Additionally, $\beta-H C G$ promoted the migration and invasion of CRC in vitro and in vivo but had no effect on the proliferation of tumor cells. Conclusion: Our study demonstrated that $\beta$-HCG was ectopically expressed in the CRC patients and its high expression correlated with poor prognosis of early-stage CRC. Additionally, it worked as an oncogene that promotes the migration and invasion of CRC by epithelial-mesenchymal transition (EMT).
\end{abstract}

\section{Introduction}

Colorectal cancer (CRC) is one of the most common cancers and the third leading cause of cancer death worldwide. CRC is classified into 4 stages (Dukes A, B, C and D) according 


\section{Cellular Physiology Cell Physiol Biochem 2018;45:237-249 \begin{tabular}{l|l} 
DOI: 10.1159/000486770 22, & $\begin{array}{l}\text { O } 2018 \text { The Author(s). Published by S. Karger AG, Basel } \\
\text { www.karger.com/cpb }\end{array}$
\end{tabular} \\ Li et al.: $\beta$-HCG Promotes Tumor Invasion and Predicts Poor Prognosis of Early-Stage Colorectal Cancer}

to the tumor invasion depth and incidence of metastasis. The 5-year survival rate of colon cancer patients diagnosed early is about $60-90 \%$, but $25 \%$ of stage II colon cancer patients will experience recurrence and progress to advanced CRC $[1,2]$. Patients with advanced CRC have a 5 -year relative survival rate of about $10 \%$ [2]. Therefore, it is important to identify sensitive and specific markers to detect the emergence of CRC as early as possible and predict the prognosis. However, to this date, there exist no effective markers for the early detection and diagnosis of CRC. While carcinoembryonic antigen (CEA) is a commonly used marker in the diagnosis and monitoring of CRC, elevated CEA levels (> $5 \mathrm{ng} / \mathrm{mL})$ was only detected in $4 \%$ stage I and $25 \%$ stage II CRC patients in a cohort study of 358 CRC patients [3]. Accordingly, CEA is an extremely poor prognostic marker for early-stage CRC due to its limited capacity for early diagnosis [3]. Therefore, it is particularly important to find novel sensitive and specific markers to detect and predict prognosis of early-stage CRC patients.

Human chorionic gonadotropin (HCG) is secreted by the syncytiotrophoblast of the placenta and facilitates embryo implantation. It consists of two subunits ( $\alpha$ and $\beta$ ) and constitutes five independent molecules in the body, including three $\alpha-\beta$ dimers and two $\beta$ monomers [4]. Among the five different molecules, free $\beta$-HCG is regarded as the specific and active subunit. It increases strikingly in the early stage of pregnancy and the majority of trophoblastic diseases have therefore been recognized as an excellent marker for both pregnancy and germ cell tumors. Interestingly, some studies reported that $\beta$-HCG was highly expressed in select non-trophoblastic solid tumors, such as hepatocellular carcinoma (HCC), renal cell carcinoma (RCC) and bladder carcinoma [5-11]. In these studies, high $\beta$-HCG expression positively correlated with tumor malignancy, which implicate that it may play a unique and important role in non-germ cell tumors.

In colorectal cancer, $\beta$-HCG expression was shown to correlate with poor prognosis of CRC patients [12-16], but to date, the specific role that $\beta$-HCG plays in CRC is unclear. In this study, we evaluated the expression of $\beta$-HCG in colorectal cancer and analyzed the association between $\beta$-HCG expression and patient outcome in early-stage CRC. We found that $\beta$-HCG may be a potential marker to predict prognosis and that its expression was positively correlated with the progression of early-stage CRC. Additionally, we validated the function of $\beta$-HCG and confirmed that it can promote the migration and invasion of CRC through epithelial-mesenchymal transition (EMT).

\section{Materials and Methods}

\section{Clinical specimens}

This study has been approved by the Institutional Review Board (IRB). A total of 136 patients who were diagnosed with early-stage CRC from Shanghai Huashan Hospital between January 2007 and December 2014 were included in our study. Each patient had to meet all four eligibility criteria: (1) The patient has had a pathologic examination confirming the presence of early-stage CRC. (2) The patient has had no treatment for cancer prior to the diagnosis. (3) The patient has no serious complications or other malignant diseases. (4) The patient and family members being informed about the illness and having given informed consent before participating in the study [17].

\section{Cell lines and $\beta$-HCG lentivirus infection}

HCT-116, HT-29, SW480 cell lines were preserved in our laboratory. HCT-116 and HT-29 were cultured with McCoy's 5A medium and SW480 with DMEM medium (Life Technologies, Carlsbad, CA) containing $10 \%$ FBS and $1 \%$ pen-strep. Lentivirus- $\beta$-HCG vector (LV- $\beta$-HCG) and its negative control (LV-NC) were purchased from Shanghai GenePharma Corporation. We infected HT-29 and SW480 with the LV- $\beta$-HCG and LV-NC, and used puromycin to select stable transfectants. RT-qPCR and western blot were used to validate the efficiency of infection.

Generation of $\beta$-HCG stable knockout cell line

SW480 cell was infected with lentiCRISPRv2-Cas9 construct carrying sgRNA targeting $\beta$-HCG (sg: ATCCCGACTCCCGGGGCCCT) and empty vector respectively. $48 \mathrm{~h}$ later, cells were selected by treating with 


\section{Cellular Physiology Cell Physiol Biochem 2018;45:237-249 \begin{tabular}{l|l} 
DOI: 10.1159/000486770 22, & $\begin{array}{l}\text { O } 2018 \text { The Author(s). Published by S. Karger AG, Basel } \\
\text { www.karger.com/cpb }\end{array}$
\end{tabular} \\ Li et al.: $\beta$-HCG Promotes Tumor Invasion and Predicts Poor Prognosis of Early-Stage Colorectal Cancer}

puromycin $(2 \mathrm{ug} / \mathrm{ml})$ for 2 weeks and continually cultured in puromycin afterwards. The knockout efficiency was validated by western blot [18].

\section{Membrane and nuclear protein extraction}

We used subcellular fractionation method [19] to extract the membrane and nuclear protein of overexpressed $\beta$-HCG in SW480 cell line. About $8 \times 10^{6}$ cells were harvested and resuspended for $5 \mathrm{~min}$ on ice in $500 \mathrm{ul} \mathrm{CLB}$ buffer. Homogenization was performed by applying 50 strokes with a motorized homogenizer. $50 \mathrm{ul}$ of $2.5 \mathrm{M}$ sucrose was added to restore isotonic conditions, and the ensuing product was subjected to differential centrifugation at $4{ }^{\circ} \mathrm{C}$. The first round of centrifugation was performed at $6300^{*} \mathrm{~g}$ for $5 \mathrm{~min}$ in a tabletop centrifuge. The pellet was resuspended in $1 \mathrm{~mL}$ TSE buffer and homogenized with 30 strokes of a motorized Teflon potter at $250 \mathrm{rpm}$. This suspension was then centrifuged at $4000^{*} \mathrm{~g}$ for $5 \mathrm{~min}$. The resulting supernatant was discarded, and the pellet washed with TSE buffer until the supernatant was clear. The resulting pellet was resuspended in $100 \mathrm{ul}$ of TSE buffer and kept at $-20^{\circ} \mathrm{C}$ (Nuclei protein). The supernatant from the first round of differential centrifugation was sedimented at $14000 \mathrm{rpm}$ for $150 \mathrm{~min}$ in a tabletop centrifuge. The resulting pellet (membrane protein) was resuspended in 80ul PBS. The supernatant (cytoplasma protein) was used without further treatments.

\section{Cell Counting Kit-8 (CCK8) proliferation assay}

HT-29 and SW480 cells (5000 cells per well) were seeded in 96-well plates. Cell Counting Kit-8 reagent (Dojindo) was added into each well and incubated for $2 \mathrm{~h}$ at $37^{\circ} \mathrm{C}, 5 \% \mathrm{CO}_{2}$. The absorbance (OD450) was measured at 5 different time points $(0 \mathrm{~h}, 24 \mathrm{~h}, 48 \mathrm{~h}, 72 \mathrm{~h}, 96 \mathrm{~h})$ and the relative absorbance was calculated by subtracting the average background signal.

\section{Colony formation assay}

SW480 $\beta$-HCG stable knockout cells and negative control cells were seeded in 6-well plates at 2000 cells/well. After 2-3 weeks, cells that demonstrated significant growth rate were fixed in 4\% paraformaldehyde for $10 \mathrm{~min}$ at room temperature and stained with $0.5 \%$ crystal violet for $30 \mathrm{~min}$. They were washed with water and dried before photographing.

\section{Transwell assay}

Transwell chambers were used to evaluate migration and invasion ability. For the migration assay, $2.5 \times 10^{4}$ tumor cells were seeded in the upper chamber with serum free medium, while the lower chamber contained $10 \%$ FBS medium, and incubated for $24 \mathrm{~h}$ at $37^{\circ} \mathrm{C}, 5 \% \mathrm{CO}_{2}$. For the invasion assay, the inserts were pre-coated with extracellular matrigel (BD, USA) at $37^{\circ} \mathrm{C}$ for one hour and then $1 \times 10^{5}$ cells were seed into each well. Finally, the media was discarded and the upper chamber was washed with PBS three times. The membrane was fixed in methanol for $10 \mathrm{~min}$ and then stained with $0.5 \%$ crystal violet for $30 \mathrm{~min}$, washed with water and dried $24 \mathrm{~h}$ before imaging.

\section{Tumor mouse model}

The animal experiments were approved by our institutional ethical board and reported according to the ARRIVE guidelines [20]. Nude BALB/c mice (SLRC Laboratory Animal) weighing approximate 20g, female, 6-8 weeks of age, were used. Animals were maintained in a laminar flow cabinet under specific-pathogenfree (SPF) conditions, kept at $26-28^{\circ} \mathrm{C}$, humidity $40-60 \%$. 3-4 mice were housed in one cage, and were fed twice per day, with the cycle of $10 \mathrm{~h}$ of day light and a $14 \mathrm{~h}$ night. $4 \times 10^{6}$ HT- 29 cells of $\beta$-HCG transfectants or NC controls were subcutaneously (s.c.) injected into nude BALB/c mice ( 5 mice for NC and 6 for $\beta$-HCG). Tumor size was measured at regular intervals twice per week, and the tumor volume was calculated using the formula: volume $=1 / 2 \times\left(\right.$ length $\times$ width $\left.^{2}\right)$. After four weeks, tumors were aseptically dissected. Tumor tissues were used for HE staining and immunohistological staining (IHC) for $\beta$-HCG (1:100, sc-271062) [21].

\section{Immunohistochemistry}

$4 \mu \mathrm{m}$-thick FFPE (formalin-fixed paraffin-embedded) tissue samples were cut for immunohistochemical staining of CRC patients (136 cases). The slides were first deparaffinized in xylene and rehydrated with gradient concentrations of alcohol under standard procedures. After rehydration, the slides were incubated with $3 \%$ hydrogen peroxide $\left(\mathrm{H}_{2} \mathrm{O}_{2}\right)$ for $30 \mathrm{~min}$ in $37^{\circ} \mathrm{C}$. The slides were then immersed in $0.01 \mathrm{~mol} / \mathrm{L}$ citrate 


\section{Cellular Physiology Cell Physiol Biochem 2018;45:237-249

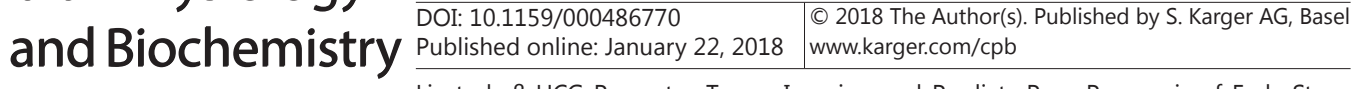 \\ Li et al.: $\beta$-HCG Promotes Tumor Invasion and Predicts Poor Prognosis of Early-Stage Colorectal Cancer}

buffer ( $\mathrm{pH} \mathrm{6.0)}$ and heated $\left(95^{\circ} \mathrm{C}\right)$ for $15 \mathrm{~min}$ for antigen retrieval and followed by $10 \%$ normal goat serum blocking for $20 \mathrm{~min}$. Subsequently, the sections were incubated with primary mouse monoclonal anti-human $\beta$-HCG antibody (dilution 1:100) (sc-271062, Santa Cruz Biotechnology) overnight at $4^{\circ} \mathrm{C}$. The next day, after washing the slides with PBS 3 times, all sections were incubated with biotin-labeled secondary antibody followed by horseradish peroxidase (HRP)-conjugated streptavidin for $1 \mathrm{~h}$ at room temperature. After applying liquid DAB+ Substrate Chromogen System (Dako), the slides were counterstained with Meyer's hematoxylin for 30-60s, and finally mounted with neutral resins and observed under the microscope [22].

\section{Western blot analysis}

Whole cell lysate, membrane protein and nuclear protein were harvested separately for western blot analysis. Anti-E-cadherin (ab40772) and anti-Vimentin (ab92547) were purchased from Abcam. Z0-1 polyclonal antibody (61-7300) was purchased from Thermo Fisher Scientific. $\beta$-catenin (D10A8) was purchased from Cell Signaling Technology. The expression level of GAPDH (sc-166574, Santa Cruz Biotechnology), $\alpha$-Tubulin(T5168, Sigma) and TBP (2H3B2, Protein tech) were used as endogenous controls.

\section{Immunofluorescence}

$1 \times 10^{4}$ SW480 cells of $\beta$-HCG transfectant or NC control were seeded into 24 -well plate containing a glass cover slip in each well. After washed in PBS with $0.1 \%$ NaN3 and blocked with $10 \%$ goat serum for $0.5 \mathrm{~h}$, cells were incubated with a mouse monoclonal anti-E-cadherin antibody (1:500, Abcam) for $1 \mathrm{~h}$. Followed with Alexa Fluor 594 goat-anti-mouse secondary antibody (1:1000, Thermo Fisher Scientific) for another 1h. Finally, nucleus was stained with DAPI (1:1000, Thermo Fisher Scientific) for 10min at room temperature. Then, the cover slip was removed to a glass slide and observed with fluorescence microscope [21].

\section{Semi-Quantitative Analysis of $\beta$-HCG Staining}

All immunohistochemistry slides were independently evaluated by two experienced pathologists, who were blinded to the patients' clinical outcome. $\beta$-HCG expression levels were determined semi-quantitatively based on the percentage of positively stained immunoreactive cells areas and the staining intensity. We defined $\beta$-HCG negative (positive number $=0$ ), low $\beta$-HCG expression (positive number $<27$ ), high $\beta$-HCG expression (positive number $>27$ ) in every $200 \times$ field. The percentage of immunoreactive cells was rated as follows: 0 points, $10 \%$; 1 point, $10 \%$ to $50 \%$; and 2 points, $50 \%$. The staining intensity was rated as 0 points (no staining or weak staining light yellow), 1 point (moderate staining yellow brown), or 2 points (strong staining brown). The overall score of $\beta$-HCG expression was the sum of points of the percentage of positively stained immunoreactive cells and the intensity, and an overall score ranging from 0 to 4 was assigned. For the statistical analysis, the patients were divided into 2 groups: a low-expression group with an overall score between 0 and 2 and a high-expression group with an overall score between 2 and 4 . The independent scores assigned by the two pathologists were combined into a final score [22]. In addition, total RNA of the FFPE tissue samples were extracted with RecoverAll Total Nucleic Acid Isolation Kit (Thermo Fisher Scientific, USA), and RT-qPCR was used for relative quantification of $\beta$-HCG.

\section{Follow-up evaluation}

Physical examination, history and serum CEA was recommended every six months for five years during the follow-up period. Abdominal CT scanning, pelvic imaging, chest imaging was recommended annually for three years. The overall survival (OS) was defined as the interval from the diagnosis of CRC to death due to any cause or to the date of last contact.

\section{Statistical analysis}

All assays were conducted triplicate. Significance was calculated by unpaired, two-tailed student's t-test, chi-square test. Kaplan-Meier survival curve analysis was performed to observe the survival rate of CRC patients. GraphPad Prism 6.0 software was used to analyze the data. ImageJ software was used for colony area and western blot quantification. 


\section{Cellular Physiology Cell Physiol Biochem 2018;45:237-249

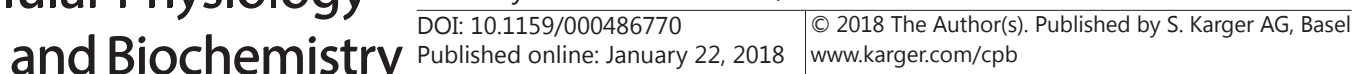 \\ Li et al.: $\beta$-HCG Promotes Tumor Invasion and Predicts Poor Prognosis of Early-Stage Colorectal Cancer}

\section{Results}

$\beta$-HCG was expressed in early-stage CRC and associated with patients' prognosis and progress

We extracted the total RNA from 32 early-stage CRC patients' FFPE samples who had 5-year follow-up data. Based on 5-year survival results, 13 out of 32 patients had poor outcomes and 19 had good outcomes. We divided patients into high- $\beta$-HCG and low- $\beta$-HCG expression groups based on mRNA expression level (Fig. 1A), and then compared the overall survival of the two groups. The high $\beta$-HCG group demonstrated shorter overall survival time than the low $\beta$-HCG group (Fig. 1B, $\mathrm{P}=0.0289$ ). Furthermore, we split these specimens into deep-muscularis group ad shallow-muscularis group based on the depth of tumor invasion and analyzed the expression of $\beta$-HCG mRNA. As expected, $\beta$-HCG mRNA was expressed at higher levels in the deep-muscularis group than in the shallow-muscularis group (Fig. 1C, $\mathrm{P}=0.0227)$. These results indicated that $\beta$-HCG was expressed in early-stage CRC tissues and associated with patients' prognosis and tumor invasion.

We further evaluated the expression of $\beta$-HCG protein in 136 colorectal tumor FFPE samples with immunohistochemistry, and the results showed that 50 out of 136 patients had positive $\beta$-HCG expression (37\%) (Fig. 2A). Placenta tissue was used as a positive control (Fig. 2B). Intriguingly, the $\beta$-HCG $(+)$ cells appeared to have a sporadic distribution and were localized to the invasive front of tumor (Fig. 2C). The clinical-pathological analysis of 136

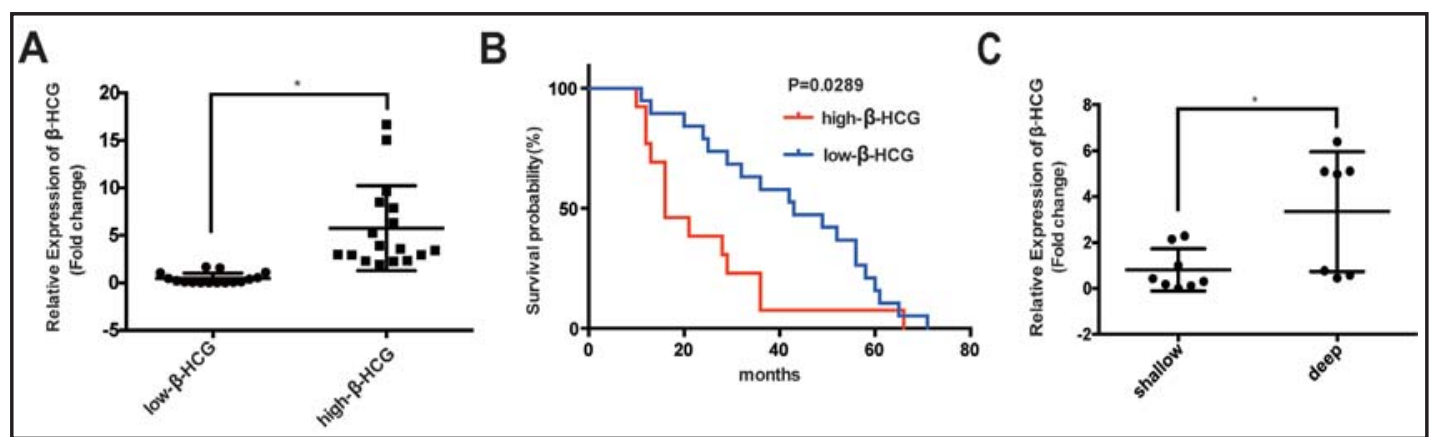

Fig. 1. $\beta$-HCG expression was positively associated with CRC invasion and poor prognosis. (A) $\beta$-HCG positive CRC tissues determined by IHC staining were split into low and high groups based on mRNA level. (B) Kaplan-Meier survival curve analysis of high $\beta$-HCG group compared to low $\beta$-HCG group. (C) Comparison of $\beta$-HCG mRNA expression according to tumor invasion depth (deep VS shallow muscular layers). ${ }^{*} \mathrm{P}<0.05$.

Table 1. Clinical characteristics of patients in $\beta$-HCG positive and negative group

\begin{tabular}{cccc}
\hline & \multicolumn{2}{c}{$\beta$-HCG expressison $\mathrm{n}=136$} & \\
\hline Characteristics & $\begin{array}{c}\text { positive } \\
\mathrm{n}=50\end{array}$ & $\begin{array}{c}\text { negative } \\
\mathrm{n}=86\end{array}$ & $\mathrm{P}$ value \\
Age & & & \\
median \pm SD $(\mathrm{X} \pm \mathrm{s})$ & $65.28 \pm 11.89$ & $66.28 \pm 12.00$ & $\mathrm{P}=0.63$ \\
Sex & & 53 & \\
male & 30 & 33 & $\mathrm{P}=0.84$ \\
female & 20 & & \\
Dukes & & 68 & \\
A\&B & 31 & 18 & \\
C & 19 & & $\mathrm{P}=0.012$ \\
negative & 31 & 70 & \\
positive & 19 & 16 & \\
\hline
\end{tabular}




\section{Cellular Physiology}

Cell Physiol Biochem 2018;45:237-249

\begin{tabular}{ll|l} 
and Biochemistry Published onIne: January 22, 2018 & $\begin{array}{l}\text { C } 2018 \text { The Author(s). Published by S. Karger AG, Basel } \\
\text { www.karger.com/cpb }\end{array}$ \\
\hline
\end{tabular}

Li et al.: $\beta$-HCG Promotes Tumor Invasion and Predicts Poor Prognosis of Early-Stage Colorectal Cancer

Fig. 2. Representative images and Quantification of $\beta$-HCG protein expression. (A) The histogram showed the patients number from negative, low to high $\beta$-HCG expression seperately in 136 CRC IHC tissues. (B) Expression of $\beta$-HCG in placenta $(100 \times)$, used as positive control. Score: $2+2$ (immunoreactive cells were $>50 \%+$ brown). (C) An expression panel of immunohistochemistry for $\beta$-HCG in CRC patients' tissues $(200 \times)$. (C-top) low expression, score: $0+0$ (immunoreactive cells were $<10 \%+$ light yellow). (C-bottom) high expression, score: $1+1$ (immunoreactive cells were $>10 \%+$ yellow). Asterisk indicated the invasive front, the positive signal increased successively from left to right lanes. (D) Differential expression of $\beta$-HCG positive numbers in different Dukes stages. (E-F) Correlation of $\beta$-HCG positive numbers with T stage (E) and lymph node metastasis (F). ${ }^{*} \mathrm{P}<0.05,{ }^{*} \mathrm{P}<0.01$.

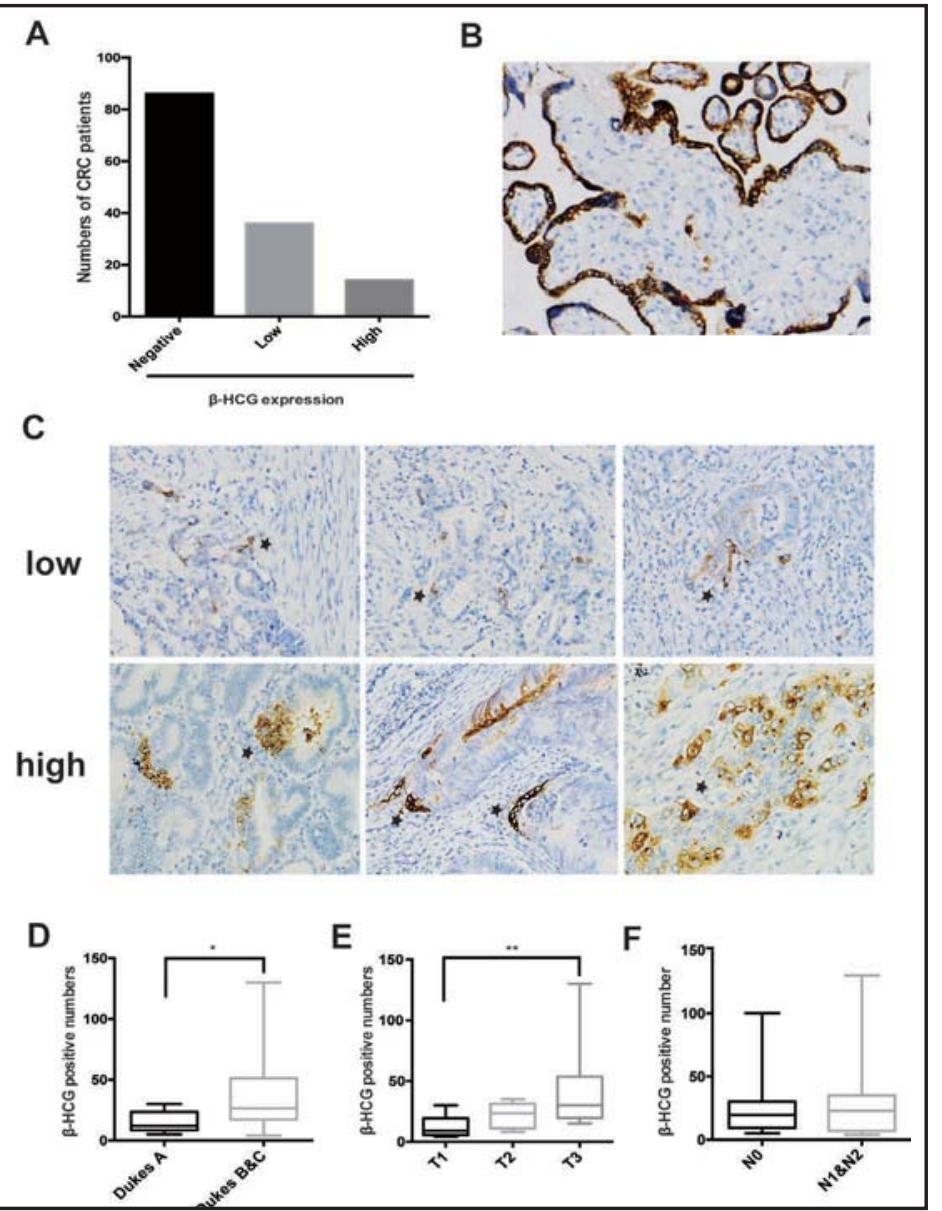

patients data showed that $\beta$-HCG protein expression was not correlated with the age and sex, but correlated with Dukes staging $(\mathrm{P}=0.031)$, and lymph node metastasis $(\mathrm{P}=0.012)$ (Table 1 ). Additionally, in the $\beta$-HCG positive group, we counted the number of $\beta$-HCG positive cells in each sample and assessed its correlation with the sample's Dukes and TNM stage. The results suggested that Dukes B\&C patients expressed more $\beta$-HCG than Dukes A group (Fig. $2 \mathrm{D}, \mathrm{P}=0.037)$. Likewise, as the T-stage progressed, the positive number of $\beta$-HCG increased correspondingly (Fig. 2E), but it was not affected by the status of lymph node metastasis (Fig. 2F).

$\beta$-HCG promoted the migration and invasion of CRC, but had no effect on the proliferation of CRC in vitro and in vivo

To investigate the function of $\beta$-HCG, we measured $\beta$-HCG expression in 7 colorectal cancer cell lines including DLD-1, HCT-8, HT-29, HCT-116, LOVO, SW480 and SW620 and used choriocarcinoma cell line JAR as positive control. Relative to JAR, all of the CRC cell lines expressed $\beta$-HCG variously (Fig. 3A-B). To further confirm, we infected $\beta$-HCG lentiviral vector and negative control into HT-29 and SW480 cells, western blot was used to validate the efficiency of $\beta$-HCG overexpression (Fig. 3C). Subsequently, the migratory and invasive abilities of these cells were assessed by Transwell assays in vitro. Migration rate increased in the LV- $\beta$-HCG group compared to control in HT-29 cells (fold change $=1.25, \mathrm{P}=0.034$ ) and in SW480 cells (fold change $=1.94, \mathrm{P}=0.013$ ) (Fig. 3D). Likewise, invasion rate increased in the LV- $\beta$-HCG group compared to control in HT-29 cells (fold change $=2.07, \mathrm{P}=0.033$ ) and in SW480 cells (fold change $=1.97, \mathrm{P}=0.045$ ) (Fig. 3E). Furthermore, CCK8 assay showed there was no significant difference in cell growth between the LV- $\beta$-HCG and LV-NC groups $(\mathrm{P}=0.893$ in HT-29, $\mathrm{P}=0.738$ in LOVO) (Fig. 3F). Consistently, in vivo mouse model, $\beta$-HCG 


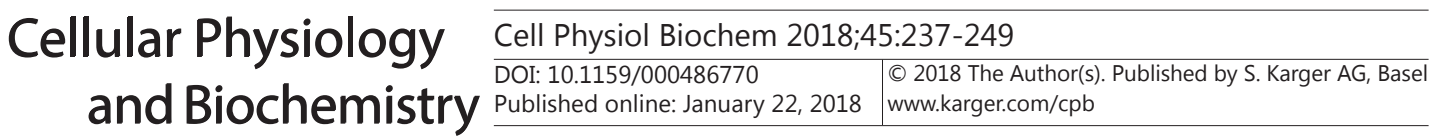

Li et al:: $\beta$-HCG Promotes Tumor Invasion and Predicts Poor Prognosis of Early-Stage Colorectal Cancer

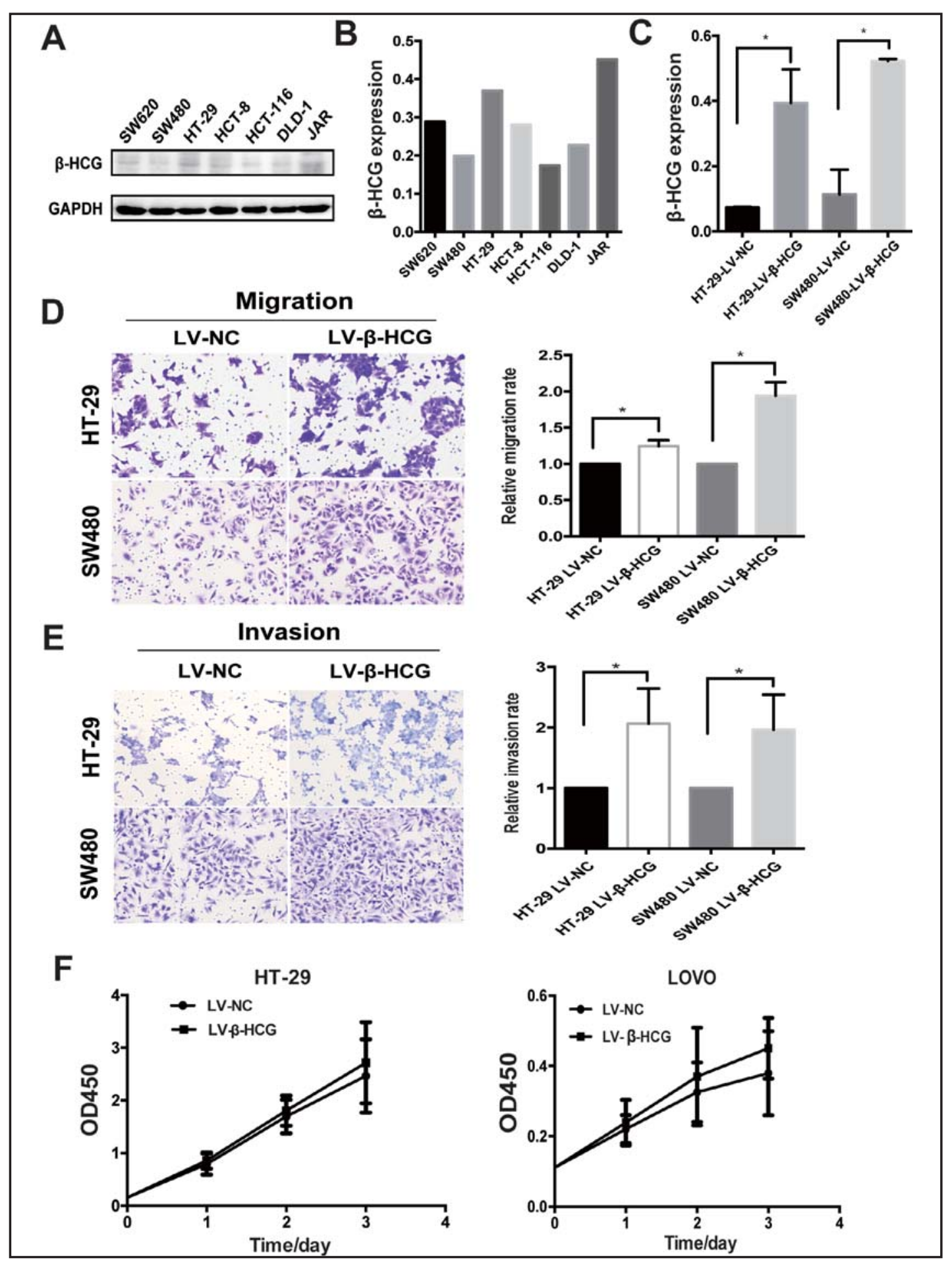

Fig. 3. Effects of $\beta$-HCG on regulating migration, invasion and cell growth in vitro. (A-B) Western blot analysis and quantification of basal $\beta$-HCG expression in CRC cell lines. JAR (Choriocarcinoma) cell was used as positive control. (C) Western blot analysis was used to validate the efficiency of $\beta$-HCG overexpression with infection of LV- $\beta$-HCG and LV-NC in HT-29 and SW480 cells (D-E) Transwell assay was used to detect the CRC migratory (D) and invasive (E) ability. Represatative images were selected randomly from 5 fields $(200 \times)$ in each group, quantified by mean of five random fields. ${ }^{*} \mathrm{P}<.05 \mathrm{VS} \mathrm{NC}$ control. (F) CCK8 assay was used to determine the effects of $\beta$-HCG on proliferation of CRC cells. Each point indicates the mean of spectrometric absorbance OD450 \pm SD of three independent experiments.

\section{KARGER}




\section{Cellular Physiology \\ Cell Physiol Biochem 2018;45:237-249 \\ \begin{tabular}{ll|l} 
and Biochemistry & Dublished online: January 22, 2018 & $\begin{array}{l}\text { @ } 2018 \text { The Author(s). Published by S. Karger AG, Basel } \\
\text { www.karger.com/cpb }\end{array}$ \\
\hline
\end{tabular} \\ Li et al.: $\beta$-HCG Promotes Tumor Invasion and Predicts Poor Prognosis of Early-Stage Colorectal Cancer}

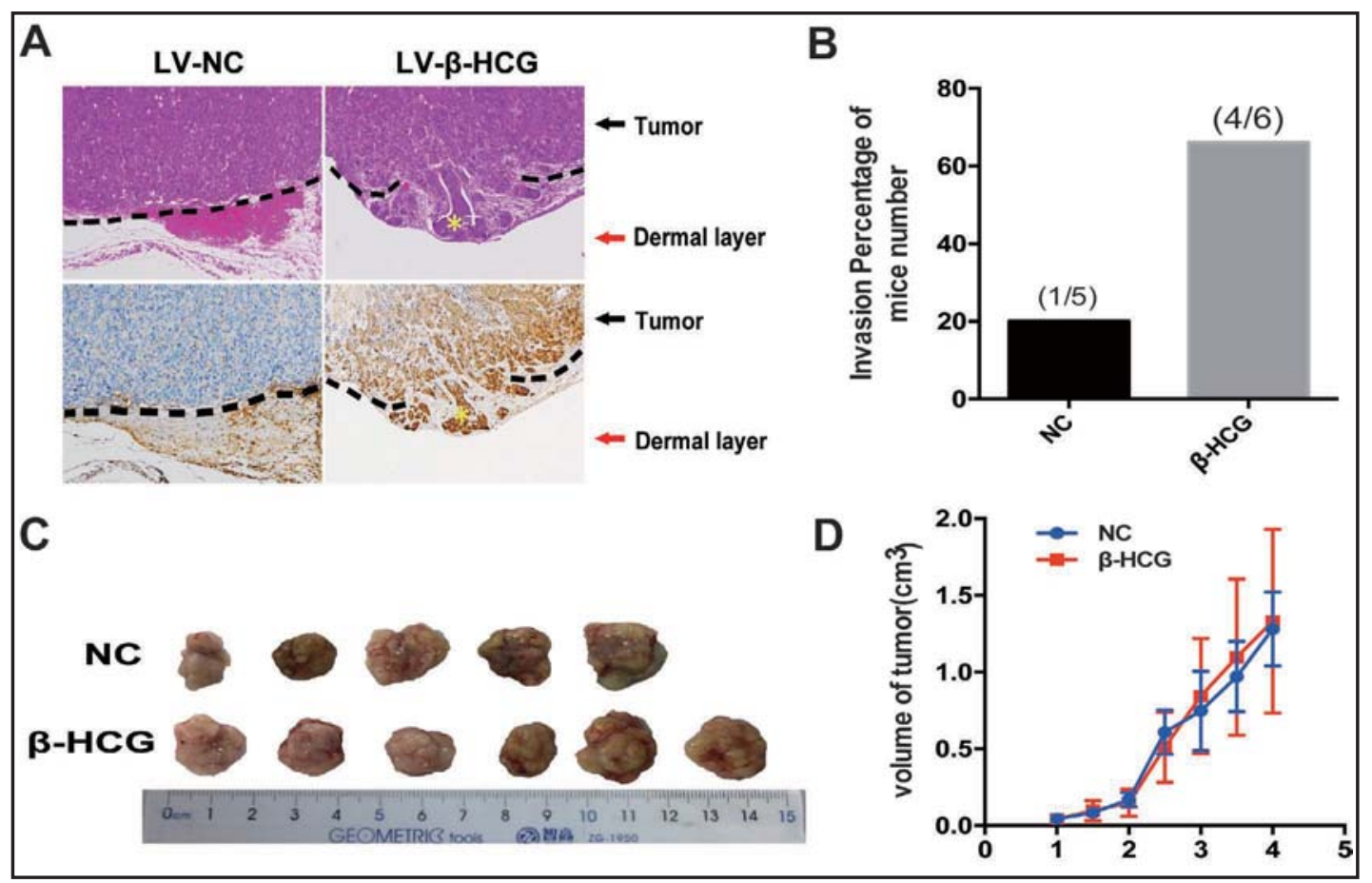

Fig. 4. $\beta$-HCG promoted the tumor cell invasion in vivo. (A) Representative images of tumor invasive front. In $\beta$-HCG group, tumor cells broke through the base membrane and invaded to subcutaneous dermal layer in both HE (100x) and IHC staining (100x), while the base membrane were unbroken in NC group. Yellow asterisk indicated the invasion area. (B) The histogram represented the percentage of mice invaded into subcutaneous dermal layer in NC and $\beta$-HCG group respectively. (C-D) In mouse model, the volume of tumors (C) and growth curve (D) of $\beta$-HCG and NC group.

overexpressed tumor cell exhibited more aggressive features at the invasive front compared to NC group. We observed tumor cells invaded into subcutaneous dermal layer with $\beta$-HCG transfectant injection, while the basement membrane in NC group was unbroken (Fig. 4A-B). As expected, the mouse model showed tumor size and growth curve had no change between $\beta$-HCG and NC (Fig. 4C-D).

Knocking out $\beta$-HCG inhibited the migration and invasion of CRC and had no effect on cell growth

In order to further confirm the function of $\beta$-HCG in vitro, we generated $\beta$-HCG stable knockout cell line in SW480 cell. The knockout efficiency was validated by western blot (Fig. $5 \mathrm{~A}$ ). Likewise, we detected the migratory and invasive abilities in the $\beta$-HCG knockout cell and the empty vector through Transwell assays. Consistent with the overexpression results, after $\beta$-HCG knockout, both the migratory (fold change $=0.46, \mathrm{P}<0.01$ ) and invasive (fold change $=0.45, \mathrm{P}<0.05$ ) abilities of tumor cells reduced significantly compared to control group (Fig. 5B). Similar to the CCK8 proliferation results, colony formation assays showed there was no evident difference of colony number and area in $\beta$-HCG stable knockout and control groups (Fig. 5C).

\section{$\beta$-HCG promoted the early invasion of CRC by EMT}

Although the expression of E-cadherin and Vimentin in whole cell lysate did not change significantly after over-expressing $\beta$-HCG (Fig. 6A), the immunofluorescence staining showed that $\beta$-HCG overexpression evidently inhibited the expression of E-cadherin in cell membrane $(\mathrm{P}=0.03)$ (Fig. 6B). To further confirm the impact of $\beta$-HCG on the distribution of E-cadherin, we extracted the membrane protein from the cells with $\beta$-HCG overexpression. From the extracted membrane proteins, we detected E-cadherin, ZO-1 and $\beta$-catenin. Compared to 
Li et al:: $\beta$-HCG Promotes Tumor Invasion and Predicts Poor Prognosis of Early-Stage Colorectal Cancer

NC, $\beta$-HCG significantly inhibited the expression of these three markers in the membrane (Fig. 6C). In addition, we detected the translocation of $\beta$-catenin to the nucleus, and found that its expression was significantly enhanced in $\beta$-HCG overexpressed group (Fig. 6D). Additionally, $\beta$-HCG knockout in SW480 cell dramatically increased E-cadherin expression (fold change $=5.2$, $\mathrm{P}<0.01)$ and significantly inhibited expression of Vimentin (fold change $=0.31, \quad \mathrm{P}<0.05$ ) (Fig. 6E). These data implied that $\beta$-HCG may promote CRC invasion by impacting cell adhesion through EMT.

\section{Discussion}

Adenocarcinoma of the colorectum is the most common malignancy of the gastrointestinal tract and is a major contributor to morbidity and mortality worldwide [1]. The 5-year survival rate of early-stage CRC patients is relatively high, and surgical resection is an effective treatment for stage I/II CRC patients. However, about onethird of early-stage CRC patients will suffer recurrence and eventually progress to advanced CRC [2]. There currently exist no standard or specific markers that can be used to effectively evaluate the risk of recurrence, predict patient outcome, and introduce chemotherapy in the early stages of the disease. Therefore, it is necessary to identify effective and accurate markers to determine the potential of CRC recurrence and predict the prognosis of these patients. In this study, we found that $\beta$-HCG was a potential marker to predict the prognosis and progression of early-stage CRC.

$\beta$-HCG mainly interacts with the luteinizing hormone/choriogonadotropin receptor (LHCGR) of the ovary and promotes the maintenance of the corpus luteum during the early stages of pregnancy [5]. As it can be detected easily in blood and other body fluids, $\beta$-HCG has been an effective marker for trophoblastic tumors and diseases. Interestingly, some studies found that $\beta$-HCG levels were elevated in the serum of patients with renal cell carcinoma [9], hepatocellular carcinoma [11], and colon cancer. Additionally, Hotakainen et al. concluded that the serum concentration but not tissue concentration of $\beta$-HCG is an independent prognostic factor in RCC [9]. Lyytinen et al. demonstrated that elevated serum concentration 
\begin{tabular}{cl|l} 
Cellular Physiology & Cell Physiol Biochem 2018;45:237-249 \\
\cline { 2 - 3 } & $\begin{array}{c}\text { DOI: 10.1159/000486770 } \\
\text { and Biochemistry }\end{array}$ & Published online: January 22, 2018 The Author(s). Published by S. Karger AG, Basel \\
\cline { 2 - 3 } & www.karger.com/cpb \\
\hline
\end{tabular}

Li et al.: $\beta$-HCG Promotes Tumor Invasion and Predicts Poor Prognosis of Early-Stage Colorectal Cancer

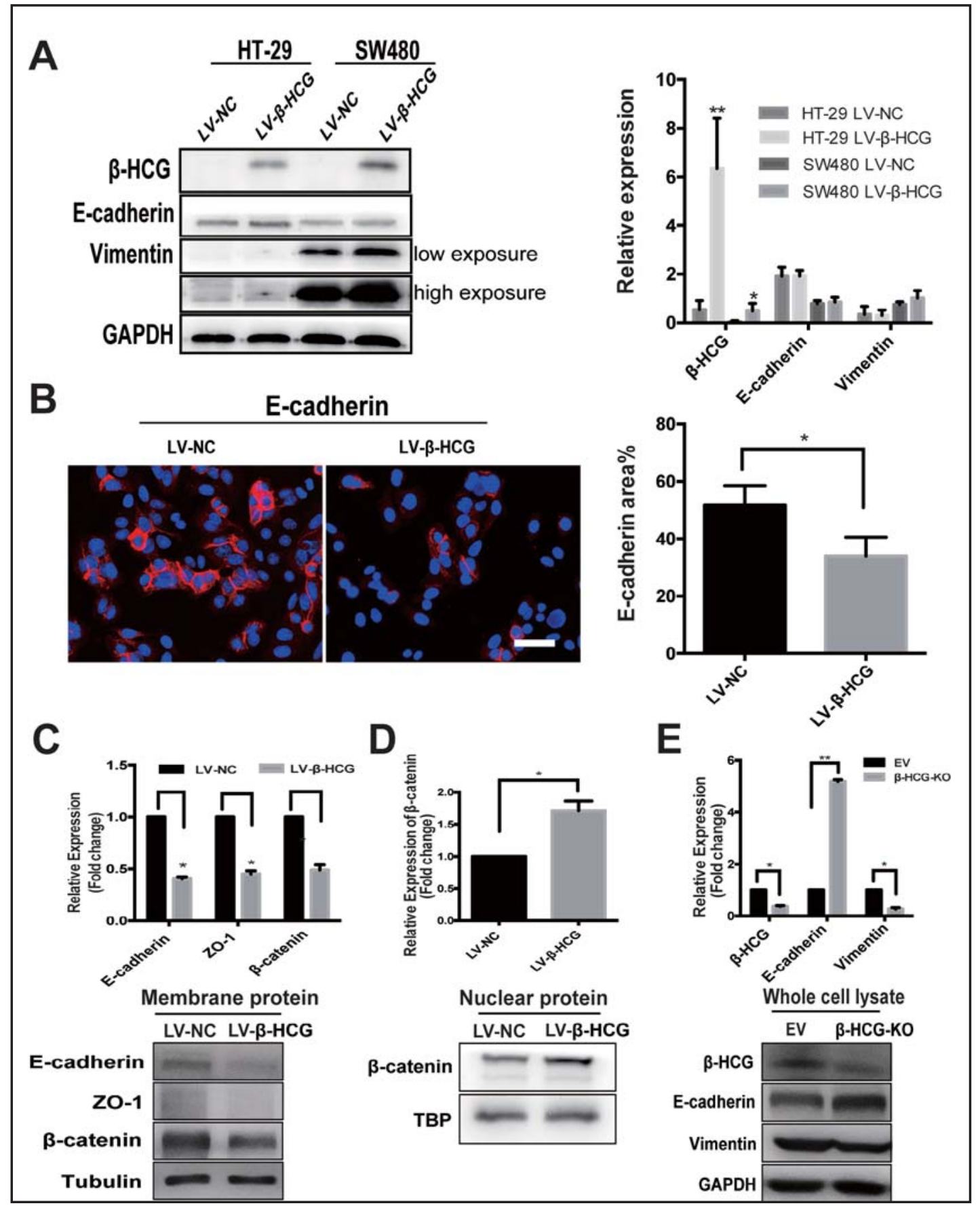

Fig. 6. $\beta$-HCG promoted the CRC invasion by EMT. (A) Western blot analysis of E-cadherin and Vimentin in whole cell lysates of $\beta$-HCG overexpression cells. (B) Immunofluorescence detection of E-cadherin in the cell membrane after up-regulating $\beta$-HCG in SW480 cell line. (C) Western blot analysis of E-cadherin, ZO-1 and $\beta$-catenin in membrane protein with $\beta$-HCG overexpression. (D) Western blot analysis of $\beta$-catenin in nuclear protein with $\beta$-HCG overexpression. (E) In $\beta$-HCG stable KO cells, E-cadherin and Vimentin were detected in whole cell lysates. ${ }^{*} \mathrm{P}<0.05,{ }^{* *} \mathrm{P}<0.01$.

of $\beta$-HCG is predictor of adverse prognosis in patients with HCC and appear to be useful adjuncts in predicting prognosis in patients with HCC [11].

Multiple lines of evidence suggested $\beta$-HCG expression was correlated with gastrointestinal malignancy as well. Birkenfeld et al. found that 25 out of 69 colorectal KARGER 


\section{Cellular Physiology Cell Physiol Biochem 2018;45:237-249

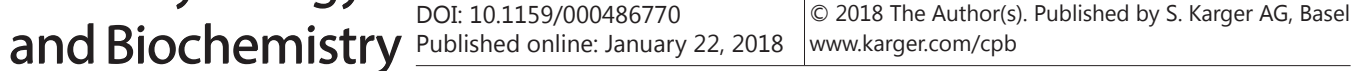 \\ Li et al.: $\beta$-HCG Promotes Tumor Invasion and Predicts Poor Prognosis of Early-Stage Colorectal Cancer}

carcinomas had elevated serum $\beta$-HCG (36.8\%) in 101 patients with malignant gastrointestinal tumors [23]. Immediately following, Yamaguchi et al. studied 194 colorectal carcinoma tissue samples with immunohistochemistry and found that the $\beta$-HCG positive rate was $22 \%$ and it was mostly expressed in late stage colorectal cancer. Based on this result, they concluded that $\beta$-HCG might be a biological marker to predict CRC prognosis [12]. Subsequently, results from Louhimo et al. and Webb et al. suggested that $\beta$-HCG could be an independent prognostic factor in advanced colorectal cancer $[14,15]$. However, neither closely studied $\beta$-HCG expression in early stages of CRC. Lundin et al. reported that there was moderate correlation between $\beta$-HCG expression in serum and tissue of CRC patients. They discovered that both serum and tissue expression of $\beta$-HCG were independent prognostic factors, but they pointed out that serum $\beta$-HCG expression levels had higher predictive power than tissue expression [16]. However, Carpelan et al. and Connelly et al. conversely proposed that serum and tissue $\beta$-HCG do not provide significant diagnostic information [24] and cannot be regarded as significant prognostic factors in stage B2 and C2 CRC [25]. Given the complex results from previous research, we aim to confirm the clinical significance of $\beta$-HCG in early-stage CRC and to reveal its function and mechanism in CRC cells. According to our results, we confirmed that $\beta$-HCG was associated with Dukes stage, especially the $\mathrm{T}$ and $\mathrm{N}$ stages. Additionally, by analyzing the correlation between the expression panel of $\beta$-HCG and the prognosis of CRC patients, we confirmed that $\beta$-HCG expression is correlated with poor prognosis in early-stage CRC. Furthermore, we compared the expression of $\beta$-HCG in early-stage CRC patients based on the invasion depth into the muscular layer, and the results implied it is significantly correlated with early tumor invasion.

Although the majority of clinical data suggested that $\beta$-HCG might be an independent prognostic predictor, the specific function and mechanism of this protein are not known. Given the widely accepted theory that $\beta$-HCG exponentially increases during embryo implantation to facilitate trophoblast invasion through a cAMP-mediated signaling pathway, we propose that $\beta$-HCG may play a similar role in early-stage CRC where it facilitates tumor invasion through a similar pathway. The results of this study are consistent with our proposed theory: by examining the distribution of the $\beta$-HCG positive cells, we found that $\beta$-HCG protein was mostly located at the invasive front of CRC tumors, the more malignant and aggressive tumor area in which the tumor cells are highly correlated with EMT [26]; while $\beta$-HCG had no influence on tumor proliferation, it did promote CRC cell migration and invasion. In addition, Li et al. reported that $\beta$-HCG promoted migration and invasion in prostate cancer by inhibiting E-cadherin and activating the ERK signaling pathway [27]. Our study also validated $\beta$-HCG did decrease the expression of E-cadherin, ZO-1 in membrane and enhance the $\beta$-catenin translocation from the membrane to nucleus. Taken together, EMT likely play a critical role in the $\beta$-HCG induced tumor invasion.

\section{Conclusion}

We confirmed that $\beta$-HCG was expressed in CRC tissues and cell lines, and that $\beta$-HCG expression was negatively correlated with the prognosis of early-stage CRC patients. Meanwhile, the expression of $\beta$-HCG was positively correlated with the Dukes stage of earlystage CRC. Furthermore, we demonstrated that $\beta$-HCG promoted the migration and invasion of CRC cells in vitro and in vivo through EMT.

\section{Acknowledgements}

We thank Dr. Qin Yan from the Department of Pathology, Yale University for his valuable suggestions and reviewing our paper. We thank Molly Gale and Andrey Buzuk from the Department of Pathology, Yale University and Mengou Zhu from Washington University School of Medicine for helping polish our article. We also appreciate the technical assistance offered by Zhonghua Zhao and Qi Chen from the Department of Pathology, Fudan University. 


\section{Cellular Physiology Cell Physiol Biochem 2018;45:237-249 \begin{tabular}{l|l|l} 
DOI: 10.1159/000486770 & (c) 2018 The Author(s). Published by S. Karger AG, Basel
\end{tabular}

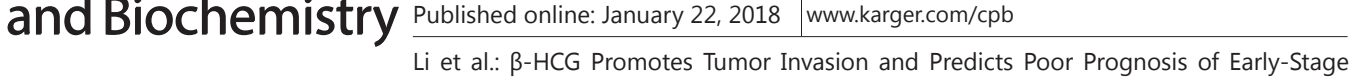 Colorectal Cancer}

Dr. Jiali Li acknowledges the support from the China Scholarship Council (Student No: 201606100186) for her visit to Yale University, where part of this work was performed.

\section{Disclosure Statement}

The authors declare no conflicts of interest.

\section{References}

1 Benson AB, Schrag D, Somerfield MR, Cohen AM, Figueredo AT, Flynn PJ, Krzyzanowska MK, Maroun J, McAllister P, Van Cutsem E, Brouwers M, Charette M, Haller DG: American Society of Clinical Oncology recommendations on adjuvant chemotherapy for stage II colon cancer. J Clin Oncol 2004;22:3408-3419.

- Brenner H, Kloor M, Pox CP: Colorectal cancer. Lancet 2014;383:1490-1502.

3 Fakih MG, Padmanabhan A: CEA monitoring in colorectal cancer. What you should know. Oncology (Williston Park) 2006;20:579-587

4 Cole LA: hCG, five independent molecules. Clin Chim Acta 2012;413:48-65.

5 Stenman UH, Alfthan H, Hotakainen K: Human chorionic gonadotropin in cancer. Clin Biochem 2004;37:549-561.

-6 Iles RK: Ectopic hCGbeta expression by epithelial cancer: malignant behaviour, metastasis and inhibition of tumor cell apoptosis. Mol Cell Endocrinol 2007;260-262:264-270.

7 Tapia-Pizarro A, Argandona F, Palomino WA, Devoto L: Human chorionic gonadotropin (hCG) modulation of TIMP1 secretion by human endometrial stromal cells facilitates extravillous trophoblast invasion in vitro. Hum Reprod 2013;28:2215-2227.

8 Nishimura R, Koizumi T, Morisue K, Yamanaka N, Lalwani R, Yoshimura M, Nakagawa T, Shii K, Hasegawa $\mathrm{K}$, Baba S: Expression and secretion of the beta subunit of human chorionic gonadotropin by bladder carcinoma in vivo and in vitro. Cancer Res 1995;55:1479-1484.

-9 Hotakainen K, Ljungberg B, Haglund C, Nordling S, Paju A, Stenman UH: Expression of the free beta-subunit of human chorionic gonadotropin in renal cell carcinoma: prognostic study on tissue and serum. Int J Cancer 2003;104:631-635.

10 Iles RK, Butler SA: Human urothelial carcinomas-a typical disease of the aged: the clinical utility of chorionic gonadotrophin in patient management and future therapy. Exp Gerontol 1998;33:379-391.

11 Lyytinen I, Lempinen M, Nordin A, Mäkisalo H, Stenman UH, Isoniemi H: Prognostic significance of tumor-associated trypsin inhibitor (TATI) and human chorionic gonadotropin- $\beta$ (hCG $\beta$ ) in patients with hepatocellular carcinoma. Scand J Gastroenterol 2013;48:1066-1073.

12 Yamaguchi A, Ishida T, Nishimura G, Kumaki T, Katoh M, Kosaka T, Yonemura Y, Miyazaki I: Human chorionic gonadotropin in colorectal cancer and its relationship to prognosis. Br J Cancer 1989;60:382-384.

13 Meduri G, Charnaux N, Spyratos F, Hacene K, Loosfelt H, Milgrom E: Luteinizing hormone receptor status and clinical, pathologic, and prognostic features in patients with breast carcinomas. Cancer 2003;97:18101816.

14 Louhimo J, Carpelan-Holmström M, Alfthan H, Stenman UH, Järvinen HJ, Haglund C: Serum HCG beta, CA 72-4 and CEA are independent prognostic factors in colorectal cancer. Int J Cancer 2002;101:545-548.

15 Webb A, Scott-Mackie P, Cunningham D, Norman A, Andreyev J, O’Brien M, Bensted J: The prognostic value of CEA, beta HCG, AFP, CA125, CA19-9 and C-erb B-2, beta HCG immunohistochemistry in advanced colorectal cancer. Ann Oncol 1995;6:581-587.

16 Lundin M, Nordling S, Carpelan-Holmstrom M, Louhimo J, Alfthan H, Stenman UH, Haglund C: A comparison of serum and tissue hCG beta as prognostic markers in colorectal cancer. Anticancer Res 2000;20:49494951.

-17 Yin MZ, Li X, Tan S, Zhou HJ, Ji W, Bellone S, Xu X, Zhang H, Santin AD, Lou G, Min W: Tumor-associated macrophages drive spheroid formation during early transcoelomic metastasis of epithelial ovarian cancer. J Clin Invest 2016;126:4157-4173. 


\section{Cellular Physiology Cell Physiol Biochem 2018:45:237-249

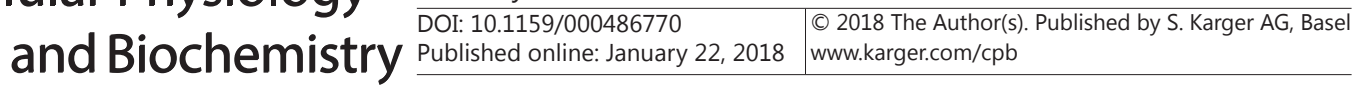

Li et al:: $\beta$-HCG Promotes Tumor Invasion and Predicts Poor Prognosis of Early-Stage Colorectal Cancer

18 Cao J, Wu LZ, Zhang SM, Lu M, Cheung WK, Cai W, Gale M, Xu Q, Yan Q: An easy and efficient inducible CRISPR/Cas9 platform with improved specificity for multiple gene targeting. Nucleic Acids Res 2016;44:e149.

19 Guillemin I, Becker M, Ociepka K, Friauf E, Nothwang HG. A subcellular prefractionation protocol for minute amounts of mammalian cell cultures and tissue. Proteomics 2005;5:35-45.

20 Kilkenny C, Browne WJ, Cuthill IC, Emerson M, Altman DG. Improving bioscience research reporting: the ARRIVE guidelines for reporting animal research. PLoS Biol 2010;8:e1000412.

-21 Zhou CX, Cui FY, Li JL, Wang DY, Wei YZ, Wu Y, Wang JP, Zhu HG, Wang SY: MiR-650 represses high-risk nonmetastatic colorectal cancer progression via inhibition of AKT2/GSK3 $\beta /$ E-cadherin pathway. Oncotarget 2017;8:49534-49547.

22 Yin MZ, Xu Y, Lou G, Hou Y, Meng F, Zhang H, Li C, Zhou R: LAPTM4B overexpression is a novel predictor of epithelial ovarian carcinoma metastasis. Int J Cancer 2011;129:629-635.

23 Birkenfeld S, Noiman G, Krispin M, Schwartz S, Zakut H: The incidence and significance of serum hCG and CEA in patients with gastrointestinal malignant tumors. Eur J Surg Oncol 1989;15:103-108.

-24 Carpelan-Holmström M, Louhimo J, Stenman UH, Alfthan H, Järvinen H, Haglund C: CEA, CA 242, CA 19-9, CA 72-4 and hCGbeta in the diagnosis of recurrent colorectal cancer. Tumour Biol 2004;25:228-234.

25 Connelly JH, Johnston DA, Bruner JM: The prognostic value of human chorionic gonadotropin expression in colorectal adenocarcinomas. An immunohistochemical study of 102 stage B2 and C2 nonmucinous adenocarcinomas. Arch Pathol Lab Med 1993;117:824-826.

-26 Grigore AD, Jolly MK, Jia D, Farach-Carson MC, Levine H: Tumor Budding: The Name is EMT. Partial EMT. J Clin Med 2016;5:e51.

27 Li Z, Li C, Du L, Zhou Y, Wu W: Human chorionic gonadotropin $\beta$ induces migration and invasion via activating ERK1/2 and MMP-2 in human prostate cancer DU145 cells. PLoS One 2013;8:e54592. 